\title{
Impact of Postharvest Storage on the Infection and Colonization of Penicillium digitatum and Penicillium expansum on Nectarine
}

\author{
Johannes Petrus Louw ${ }^{1,2, \dagger}$ and Lise Korsten ${ }^{1,2, \dagger}$ \\ ${ }^{1}$ Department of Plant and Soil Sciences, University of Pretoria, Hillcrest 0083, South Africa \\ ${ }^{2}$ University of Pretoria, Pretoria 0028, South Africa
}

\begin{abstract}
Very few studies have investigated the host-pathogen interaction of Penicillium spp. on nectarine. Penicillium digitatum was identified as pathogenic and highly aggressive on nectarine. A strong association was made with host age/ripeness. This points to a new mechanism or life strategy used by $P$. digitatum to infect and colonize previously thought nonhosts. The aim of this study was to determine the effect of postharvest storage of nectarine on the infection and colonization of $P$. digitatum and Penicillium expansum at molecular and physical (firmness and $\mathrm{pH}$ ) levels. The impact of environmental conditions (cold storage) and pathogen pressure (inoculum load) was also investigated. Although disease incidence was much lower, lesions caused by $P$. digitatum were similar in size to those caused by $P$. expansum on freshly harvested nectarine. Disease incidence and lesion diameter significantly increased (larger than P. expansum) on longer stored fruit. Cold storage had the largest effect on P. digitatum. Inoculum load had a meaningful effect on both Penicillium

(similar to initial $\mathrm{pH}$ of the host) $\mathrm{pH}$ of infected tissue. The polygalacturonase $(P G)$ gene and creA were upregulated by $P$. digitatum on 7-day postharvest fruit (other genes were unaffected). It partly explains the larger lesions on older or riper fruit. A different expression profile was observed from $P$. expansum: strong downregulation in $P G$ and slight upregulation in $p a c C$. Very different life strategies were used by the two Penicillium spp. when infecting nectarine. Unlike what is known on citrus, $P$. digitatum showed an opportunistic lifestyle that takes advantage of specific host and environmental conditions. It is largely still unclear (gene expression) what specifically triggers the increase in disease incidence (infection) and lesion diameter (colonization) of $P$. digitatum on older or riper fruit. The differences between in vivo and in vitro studies make it difficult to directly correlate results. Additional research is still needed to differentiate and understand the infection and colonization of these pathogens on the same host.
\end{abstract} spp. Storage significantly affected $\mathrm{pH}$ modulation and gene expression. The pathogens not only decreased but also, increased and maintained

Keywords: ddPCR, stone fruit

Globally, >20.73 million metric tons of nectarines (Prunus persica [L.] Batsch var. nucipersica [Suckow] C. Schneider) and peaches were produced during 2016 and 2017 (USDA 2017). Nectarines are climacteric fruit with high relative perishability. The fruit wound easily and have a range of postharvest pathogens (i.e., Monilinia spp., Rhizopus spp., Mucor spp., and Penicillium spp.) that can cause decay and contribute to losses (Crisosto and Mitchell 2011; Kader 2011). Monilinia spp. are the most important postharvest pathogens of apricot, peach, and nectarine, but Penicillium expansum Link 1809 is also recognized (losses and mycotoxin production) (Pitt and Hocking 2009; Snowdon 2010). Findings have drawn attention to other Penicillium spp. that can pose a risk to the fruits (Louw and Korsten 2016). Other pathogenic Penicillium spp. of nectarine include Penicillium crustosum Thom 1930, Penicillium digitatum (Pers.: Fr.) Sacc. 1883, and Penicillium solitum Westling 1911 (Louw and Korsten 2016). Little is known of $P$. crustosum and $P$. digitatum, although they pose a realistic threat in the export chain (Louw and Korsten 2016; Navarro et al. 2011; Restuccia et al. 2006). P. digitatum was able to produce the largest

${ }^{\dagger}$ Corresponding authors: J. P. Louw; pieterjplouw@gmail.com, and L. Korsten; lise.korsten@up.ac.za

Funding: This work is based on research supported in part by the National Research Foundation (NRF) of South Africa (Unique Identification: 78566 [NRF Research and Innovation Support and Advancement grant for the ABI3500], Unique Identification: 105649 [NRF Research and Innovation Support and Advancement National Equipment Programme grant for the QX200 AutoDG droplet digital polymerase chain reaction system], and Unique Identification: 97884 [student support]).

The author(s) declare no conflict of interest.

Accepted for publication 22 January 2019.

(C) 2019 The American Phytopathological Society lesions on nectarine and plum. Lesions caused by $P$. solitum were small, and decay can be regarded as negligible (Louw and Korsten 2016).

Decay linked to $P$. crustosum is understandable, because it is a pathogen with a broad host range (Pitt and Hocking 2009). Decay caused by $P$. digitatum and the severity thereof were less expected. This species, closely associated with citrus (Frisvad and Samson 2004; Stange et al. 2002), was identified as highly aggressive on pome and stone fruits (Louw and Korsten 2014, 2016). In this case, it was able to cause much larger lesions than $P$. expansum within a shorter period of time. $P$. digitatum is also known to be present in these fruit environments (Ma et al. 2003; Scholtz and Korsten 2016). Disease incidence and severity can be higher on older or riper fruit (Louw and Korsten 2014, 2016).

Riper fruit will be not only physiologically more favorable (i.e., carbon and nitrogen levels and $\mathrm{pH}$ changes) but also, more susceptible (weaker host defense) to infection and colonization (Prusky 1996; Prusky et al. 2016). These changes will affect host-pathogen interactions (Bi et al. 2016; Prusky et al. 2016). Penicillium spp. are described as acidifying pathogens via the release of organic acids and uptake of ammonium. Modulating environmental $\mathrm{pH}$ via this manner was connected to the upregulation of pathogenicity and virulence factors. The production and secretion of secondary metabolites, such as mycotoxins and pectolytic enzymes, lead to cell necrosis and tissue maceration of the host (i.e., pome and citrus fruits) (Prusky et al. 2004; Sánchez-Torres and González-Candelas 2003; Yao et al. 1996; Zhang et al. 2013).

The production of ethylene or its precursors was shown to play an important role during the infection and colonization of $P$. digitatum and P. expansum (Barad et al. 2016b; Chalutz and Lieberman 1977; Jia et al. 1999; Marcos et al. 2005). Understandably, previous fruitPenicillium interaction research focused on apple-P. expansum and citrus- $P$. digitatum (Barad et al. 2016a, 2016b; Bi et al. 2016; Marcos et al. 2005; Prusky et al. 2004; Sánchez-Torres and GonzálezCandelas 2003; Zhang et al. 2013). Very little research has been done on stone fruits. The new host-pathogen association of $P$. digitatum 
on nectarine gives reason to further investigate the mechanisms involved in this interaction. The aim of this study is to determine the effect of postharvest storage of nectarine on the infection and colonization of $P$. digitatum and $P$. expansum at molecular (gene expression) and physical (fruit firmness and $\mathrm{pH}$ ) levels. The impact of environmental conditions (cold storage) and pathogen pressure (inoculum load) will also be investigated.

\section{Materials and Methods}

Fruit origin and handling. Sunlite nectarine was selected based on availability. Fruit of similar size, maturity, and quality was used for trials. Fruit originated from a commercial farm in the Waterberg region in the Limpopo Province during the 2016 and 2017 growing season. The fruit was harvested mature (industry guidelines [DAFF 2013]) and untreated (postharvest). Fruit was collected, transported to University of Pretoria plant pathology laboratories, and placed in cold storage $\left(5.3 \pm 0.5^{\circ} \mathrm{C} ; 83.2 \pm 2.5 \% \mathrm{RH}\right)$. Fruit was removed in late afternoon to climatize overnight for trial inoculation the next day. Fruit was stored at ambient conditions $\left(23.8 \pm 0.6^{\circ} \mathrm{C} ; 65.7 \pm\right.$ $9.1 \% \mathrm{RH})$ to produce three different postharvest storage periods (1, 4 , and 7 days postharvest) before inoculation.

Penicillium spp. cultures. Cultures of $P$. digitatum and $P$. expansum originated from Louw and Korsten (2016). These isolates were made from symptomatic fruit, plated on malt extract agar (MEA; Merck, Biolab Diagnostics), single-spore isolated, preserved in sterilized distilled water, and stored at ambient temperature. Isolates were cultured on MEA and incubated at $25^{\circ} \mathrm{C}$ for 5 to 7 days. Conidia were harvested in sterilized Ringer's solution (Merck) with $0.05 \%$ Tween 80 (Associated Chemical Enterprises). A hemocytometer was used to determine conidial concentrations.

Quality parameters of fruit. Three replicates were used to determine fruit indices. This was done prior to inoculation for each storage period. Weight (grams), firmness $(\mathrm{N})$, sugar content $\left({ }^{\circ} \mathrm{Brix}\right), \mathrm{pH}$, titratable acidity (TA; percentage), and sugar/acid ratio were of interest. Firmness was determined using a Turoni TR 53205 penetrometer (T.R. Turoni S.R.L.) fitted with a 5-mm stainless steel cylindrical probe. Sugar content was measured from blended fruit juice (whole) using an ATAGO pocket refractometer (Labex). The same juice was used to measure $\mathrm{pH}$ with a Hanna HI1131 electrode coupled to a Hanna HI2210 pH meter (Hanna Instruments). Ten milliliters of juice with 0.1 mol liter $^{-1} \mathrm{NaOH}$ and phenolphthalein as indicator was used to determine TA, and TA was expressed in malic acid (percentage). Sugar/acid ratio was calculated as ${ }^{\circ}$ Brix/TA.

Effect of storage on infection and colonization of Penicillium spp. Fruit was dipped into $0.5 \%$ sodium hypochlorite for \pm 5 min for surface sterilization. Thereafter, it was rinsed (two times) via dipping into sterilized tap water ( $5 \mathrm{~min}$ each) and allowed to air dry on a disinfected table. Inoculation of fruit was as described by Louw and Korsten (2014, 2016). The fruit (10 replicates for each storage period and Penicillium spp.) was wound inoculated via pipetting $20 \mu \mathrm{l}$ conidial suspension $\left(10^{5}\right.$ conidia per $\left.1 \mathrm{ml}\right)$ or control solution (sterile Ringer's solution with $0.05 \%$ Tween 80 ) into wound sites $(1.5 \times 3 \mathrm{~mm})$. Two wounds for inoculation were made on opposite sides of each fruit using a sterilized micropipette (20 to $100 \mu \mathrm{l})$. Fruit was randomized and incubated for 5 days at ambient conditions $\left(24.00 \pm 0.62{ }^{\circ} \mathrm{C} ; 68.32 \pm 7.20 \% \mathrm{RH}\right)$. Lesion sizes were recorded after 2,4 , and 5 days of incubation by measuring the horizontal and vertical (fruit held upright) lesion diameters. Advanced symptom development was recorded from fruit that was incubated for longer periods of time. The trial was repeated.

Effect of storage and inoculum load on decay. Conidial suspensions as well as sterilization and wounding of fruit were completed as described earlier. Initial suspensions were prepared at $10^{6}$ conidia per $1 \mathrm{ml}$ and diluted to $10^{5}$ and $10^{4}$. Five replicates were used for each combination of storage period, Penicillium spp., and conidial concentration (including control). Fruit was randomized and incubated under ambient conditions for 5 days. The recording of lesion diameter was as described earlier. The number of days required for mycelia and conidia formation was noted. The trial was repeated.

Effect of inoculum load and cold storage on decay. Conidial suspensions as well as sterilization and wounding of fruit were completed as described earlier. Five replicates were used for each combination of storage condition, Penicillium spp., and conidial concentration (including control). For ambient storage, fruit was randomized and incubated on a disinfected table for 5 days, and results were recorded as described earlier. For cold storage, fruit was randomized on a disinfected trolley and incubated in a cold room $\left(5.26 \pm 0.52^{\circ} \mathrm{C} ; 83.16 \pm 2.51 \% \mathrm{RH}\right)$. Results were recorded every 5 th day from 16 to 31 days postinoculation. The development of symptoms was noted during the incubation time. The trial was repeated.

Firmness and $\mathbf{~ p H}$ of infected sites. Fifteen fruits for each storage period and Penicillium spp. were wound inoculated $\left(10^{5}\right.$ conidia per $1 \mathrm{ml}$ ). Control fruits were included. Sterilization, wounding, randomization, and incubation (ambient) of fruit and preparation of conidial suspensions were as described earlier. Of the 15 inoculated fruits for each combination of storage period and Penicillium spp. or control, 3 fruits were used for each day over a 5-day incubation period to measure firmness and $\mathrm{pH}$ at inoculated sites. Firmness was measured with a penetrometer by directly piercing into the inoculated site. The skin at inoculated sites was not removed before measurements. The $\mathrm{pH}$ was measured using a Hanna FC200 pH electrode (Hanna Instruments) fitted to a Hanna HI2210 $\mathrm{pH}$ meter by direct placement into an inoculated site. The $\mathrm{pH}$ at uncolonized areas (maximum distance away from inoculated sites) was also measured. The trial was repeated.

Absolute quantification of genes. Up to 20 fruits were wound inoculated with each Penicillium spp. $\left(10^{5}\right.$ conidia per $\left.\mathrm{ml}\right)$ or control solution for each storage period. Sterilization, wounding, randomization, and incubation (ambient) of fruit and preparation of conidial suspensions were as described earlier. Healthy (from control fruit) and infected tissue at the inoculated sites was sampled after 24 and $48 \mathrm{~h}$ of incubation. A sterilized cork borer (8-mm diameter) was used to isolate inoculated sites. Tissue samples were immediately dropped into liquid nitrogen to snap freeze. Samples were placed in sterilized Bijoux or McCartney bottles and stored at $\leq-72^{\circ} \mathrm{C}$. The trial was repeated to produce three biological replicates for each combination of storage period and Penicillium spp. or control.

Samples from 1- and 7-day postharvest fruit were selected for processing. Additional samples were kept in storage for possible future work. The selected samples were ground in a sterilized and cooled (liquid nitrogen) KCG201S coffee grinder; 100 to $150 \mathrm{mg}$ homogenized tissue was used for total RNA extraction by means of the RNeasy Plant Mini Kit (Qiagen). Total RNA quantity was determined with the Qubit 2.0 Fluorometer (Invitrogen, Life Technologies) using the Qubit RNA HS Assay Kit (Invitrogen, Life Technologies). RNA analysis was done using the Agilent 2100 bioanalyzer (Agilent Technologies, Inc.). Complementary DNA (cDNA) synthesis was done with $1 \mu \mathrm{g}$ total RNA using the iScript Advanced cDNA Synthesis Kit for RT-qPCR (Bio-Rad Laboratories, Inc.). Cycle conditions for reverse transcription were $42^{\circ} \mathrm{C}$ for $30 \mathrm{~min}$ and $85^{\circ} \mathrm{C}$ for $5 \mathrm{~min}$.

Gene-specific primers (Table 1) were designed using Primer 3+ software (Untergasser et al. 2007). Polygalacturonase $(P G)$ gene, 1-aminocyclopropane-1-carboxylic acid deaminase (ACCD) gene, pacC, and $c r e A$ were selected based on their association with fruit ripening (Barad et al. 2016b; Chalutz and Lieberman 1977; Jia et al. 1999) and/or pH modulation (Prusky et al. 2004, 2016; Sánchez-Torres and González-Candelas 2003; Yao et al. 1996; Zhang et al. 2013). Although reference genes and normalization are not mandatory for droplet digital polymerase chain reaction (ddPCR) (Zmienko et al. 2015), it was found to be necessary owing to the nature of our experiments. $\beta$-actin was included as a reference gene. Only two technical replicates were needed for experiments owing to the high sensitivity and low error of the QX200 AutoDG ddPCR system (Bio-Rad Laboratories, Inc.).

The QX200 AutoDG ddPCR system includes four main steps: set up of polymerase chain reaction (PCR) reactions in a ddPCR 96-well PCR plate, generation of droplets in the QX200 AutoDG, thermal cycling, and absolute quantification of samples in the QX200 Droplet Reader. QX200 ddPCR EvaGreen Supermix (Biotium, Inc., BioRad Laboratories, Inc.) was used to set up PCR reactions. Samples 
were 10 or $10^{2}$ diluted depending on expression levels. The detection limit of ddPCR depends on the number of negative droplets. A PX1 PCR Plate Sealer (Bio-Rad Laboratories, Inc.) was used to seal plates before and after droplet generation. A C1000 Touch thermal cycler (Bio-Rad Laboratories) was used for amplification. Cycle conditions included 1 cycle at $95^{\circ} \mathrm{C}$ for $5 \mathrm{~min}$ (enzyme activation), 40 cycles at $95^{\circ} \mathrm{C}$ for $30 \mathrm{~s}$ (denaturation) and $54.5^{\circ} \mathrm{C}$ for $1 \mathrm{~min}$ (annealing/ extension), and 1 cycle at $4^{\circ} \mathrm{C}$ for $5 \mathrm{~min}$ and $90^{\circ} \mathrm{C}$ for $5 \mathrm{~min}$ (signal stabilization). Samples were held at $4^{\circ} \mathrm{C}$. Thereafter, samples were transferred to the droplet reader. The QuantaSoft Software (BioRad Laboratories, Inc.) was used for data analyses.

Reisolation, preservation, and identification. Two isolates for both Penicillium spp. were made from symptomatic fruit for each experiment from the postharvest storage and inoculum load trials. The isolates were cultured on MEA, purified (single-spore isolation), identified via DNA sequencing ( $\beta$-tubulin), and preserved in sterilized $10 \%$ glycerol stored at or below $-70^{\circ} \mathrm{C}$ (cryopreservation) as described by Louw and Korsten (2015). The identity of the cDNA sequences was also confirmed before downstream application. Sequence analysis was conducted with the ABI3500/3500XL Genetic Analyzer (Applied Biosystems). The DNA Sequencing Facility of the Faculty of Natural and Agricultural Sciences at the University of Pretoria was used to confirm species identity. The preserved isolates with DNA sequence identity were added to the Penicillium culture collection at the University of Pretoria.

Statistical design and data analysis. The trials determining the effect of different inoculum concentrations as well as storage periods and conditions were completed twice. The other trials were completed three times. Randomization was done according to the complete randomized design. Each inoculated fruit produced four pseudoreplicates (horizontal and vertical lesion diameter measurements from two inoculated sites, each at an opposite sides of a fruit), which were averaged into a single replicate. Statistical Analysis System (version 9.4; SAS Institute Inc.) was used to determine the analysis of variance. Data were evaluated for normal distribution. The similarity between trial repeats was determined using Bartlett's test for homogeneity. In the case of nonsignificant difference $(P>$ $0.05)$, trial repeats were pooled. Fisher protected least significant difference was used to separated means.

\section{Results}

Quality parameters of fruit. The farmer should have determined harvest dates based on industry guidelines (DAFF 2013). The fruit were, however, observed to be at an advance mature stage after they were harvested. It would have been helpful to measure ethylene production and/or index of absorbance difference measurements for the different storage periods, but limitations prevented it. Fruit indices for trial repeats were not significantly different $(P=0.22$ to 0.85$)$. All except for ${ }^{\circ}$ Brix $(P=0.37)$ indicated that the fruit became riper when stored at ambient conditions $(P<0.003)$. Weight, firmness, and TA decreased, whereas $\mathrm{pH}$ and sugar/acid ratio increased (Fig. 1).

Effect of storage on infection and colonization of Penicillium spp. Trial repeats were not significantly different $(P>$ 0.76). The interaction effect between storage period and Penicillium spp. was significant $(P<0.0001)$. Lesions caused by $P$. digitatum were larger on longer stored fruit, quickly surpassing those of P. expansum in size on 4- and 7-day postharvest fruit (Fig. 2). The 7-day postharvest fruit test was terminated after 4 days of incubation because of complete or near-complete decay of fruit. Disease incidence for $P$. expansum was $100 \%$ for all storage periods, whereas that of $P$. digitatum increased (Fig. 2). Blue conidia from $P$. expansum were observed as early as 3 days after incubation, whereas the lime green conidia produced by $P$. digitatum were first observed after 4 days (7-day postharvest fruit) or 5 days (1- and 4-day postharvest fruit) of incubation (Fig. 3). After sporulation started, copious amounts of conidia were produced within a short period of time.

Effect of storage and inoculum load on decay. Trial repeats were not significantly different after 4 days of incubation $(P=0.96)$. There was a significant interaction between Penicillium spp., storage period, and inoculum load after $2(P=0.04)$ and 4 days $(P=0.004)$ of incubation. $P$. digitatum caused larger lesions than $P$. expansum for all concentrations on 7-day postharvest fruit but not necessarily on 1-day postharvest fruit (Fig. 4). Lesions were larger for both species when fruit was stored longer and inoculum loads were higher. Disease incidence for $P$. digitatum was low on 1-day postharvest fruit (10 to $45 \%$ ) but high on 7-day postharvest fruit (100\%). P. expansum repeatedly expressed a $100 \%$ disease incidence for all conditions.

Effect of inoculum load and cold storage on decay. Trial repeats were not significantly different after $5(P=0.65)$ and 31 days $(P=$ 0.47) of incubation. The interaction of inoculum load and storage condition had a significant effect on lesions caused by the Penicillium spp. (Fig. 5). P. digitatum was unable to cause lesions under cold storage. Cold storage significantly reduced lesion development (size) and disease incidence of $P$. expansum. Disease incidence decreased from the usual $100 \%$ (ambient and $\left.10^{6}\right)$ to $95 \%\left(10^{5}\right)$ and $65 \%\left(10^{4}\right)$ owing to cold storage.

Firmness and $\mathbf{p H}$ of infected sites. Trial repeats were not significantly different based on the firmness of infected tissue (lesions; $P=$ 0.32 to 0.43 ). Measurements for fruit that incubated for 4 and 5 days were disregarded (Fig. 6). The firmness at the lesion sites of these fruit increased owing to large mycelial masses that developed (growth) under the inoculated sites. In the case of control fruit, longer-incubated fruit was dryer, and skin was more elastic (skin was not removed for these experiments). Storage significantly affected lesion firmness $(P<0.0001)$. The effect was also different depending on Penicillium spp. $(P<0.0001)$. Lesion firmness of $P$. digitatum deteriorated slower for 1-day postharvest fruit but not necessarily for 4- or 7-day postharvest fruit when comparing it with that of $P$. expansum. For instance, with 1-day postharvest fruit, $P$. digitatum lowered firmness by $27.14 \%$ over 2 days of incubation, whereas $P$. expansum lowered it by $64.89 \%$. Results were, however, comparable for the Penicillium spp. on 7-day postharvest fruit (58.70 versus $55.97 \%$, respectively).

Trial repeats were not significantly different based on $\mathrm{pH}$ measurements from 2 to 5 days of incubation $(P=0.30$ to 0.97$)$. Similar to firmness, storage significantly affected the $\mathrm{pH}$ of infected sites $(P<$ $0.03)$, and the effect was Penicillium spp. dependent $(P<0.01)$. The $\mathrm{pH}$ of $P$. digitatum lesions remained relatively consistent on 1day postharvest fruit but decreased on 4- and 7-day postharvest fruit

Table 1. Primers used for gene expression analysis of the Penicillium spp. (Penicillium digitatum and Penicillium expansum)

\begin{tabular}{|c|c|c|c|}
\hline Primers & Forward $\left(5^{\prime}\right.$ to $\left.3^{\prime}\right)$ & Reverse $\left(5^{\prime}\right.$ to $\left.3^{\prime}\right)$ & Target $^{\mathrm{z}}$ \\
\hline $\mathrm{Pg} 2 \mathrm{Pd}$ & agcctgaccaactccaacat & ctccttagcgccatcgatac & $P G$ of $P$. digitatum; synthesis of $\mathrm{PG}$ \\
\hline $\mathrm{Pg} 1 \mathrm{Pe}$ & aaaggcaggttgctccagta & aggccagaccagtcaaatcc & $P G$ of $P$. expansum; synthesis of $\mathrm{PG}$ \\
\hline ACCDPd & cggttcttgtttgtgctgtg & cettcctcttcgcgtcct & $A C C D$ of $P$. digitatum; ethylene biosynthesis \\
\hline ACCDPe & acggtgcttgtttgtgctgt & gcctcaacagtggcagaag & $A C C D$ of $P$. expansum; ethylene biosynthesis \\
\hline PacCPd & ccggtgagctactgccttg & caggttgaggttgttggtgct & PacC: $\mathrm{C} 2 \mathrm{H} 2$ transcription factor of $P$. digitatum; $\mathrm{pH}$ regulation \\
\hline $\mathrm{PacCPe}$ & ggacatttcccaggatagca & gatagagcggggtcaatcag & PacC: $\mathrm{C} 2 \mathrm{H} 2$ transcription factor of $P$. expansum; $\mathrm{pH}$ regulation \\
\hline CreAPd & cgcaagtagagcgagacgaccaca & tgcatacgcggaaagcgaagg & CreA: $\mathrm{C} 2 \mathrm{H} 2$ transcription factor of $P$. digitatum; carbon regulation \\
\hline CreAPe & cgcattcaaacgatgacgatgatggct & aggaaggagcagtggagttgggtg & CreA: $\mathrm{C} 2 \mathrm{H} 2$ transcription factor of $P$. expansum; carbon regulation \\
\hline$\beta a P$ & cttcccgatggacaggtcat & tggataccgccagactcaag & $\beta$-actin of $P$. digitatum and $P$. expansum; reference \\
\hline
\end{tabular}

${ }^{\mathrm{z}} A C C D, 1$-aminocyclopropane-1-carboxylic acid deaminase; $P G$, polygalacturonase. 
(Fig. 6). Equilibrium was eventually reached at roughly 3.4. For $P$. expansum-infected fruit, $\mathrm{pH}$ of lesions increased on 1- and 4-day postharvest fruit but decreased on 7-day postharvest fruit. Here, equalization took place at 3.6 but decreased to a nearly similar $\mathrm{pH}$ to $P$. digitatum with 7-day postharvest fruit. The $\mathrm{pH}$ of control fruit continually increased from 3.4 (1-day postharvest fruit at 1 day of incubation) to 4 ( 7 days postharvest at 4 days of incubation). The $\mathrm{pH}$ of colonized tissue (lesions) was generally lower than the $\mathrm{pH}$ of uncolonized (infected fruit) tissue and the $\mathrm{pH}$ of healthy tissue (control fruit). There were some exceptions with 1-day postharvest fruit (Table 2). Differences in $\mathrm{pH}$ between colonized and uncolonized tissue $\left(\Delta_{\mathrm{pH}}\right.$ colonized-uncolonized $)$ increased (4 days of incubation), and differences between $\Delta_{\mathrm{pH}}$ colonized-uncolonized and colonized versus control $\left(\Delta_{\mathrm{pH}}\right.$ colonized-control $)$ were small $\left(\Delta \Delta_{\mathrm{pH}}\right)$.

Absolute quantification of genes. Trial repeats were not significantly different based on gene expression profiles ( $P=0.51$ to 0.94$)$. Absolute and normalized data (reference gene) are displayed (Fig. 7). The high expression of the reference gene led to negative log values when normalization was completed. Only normalized data will be discussed. Expression of $A C C D$ increased and expression of pacC decreased for $P$. digitatum over incubation time. Expression of $P G$ and pac $C$ decreased for $P$. expansum over incubation time, whereas expression of $A C C D$ increased for $P$. expansum over incubation time. The interaction of Penicillium spp. and storage period was significant for the expression of $P G(P<0.001)$ and creA $(P=0.04)$. They were higher on 7-day postharvest fruit infected with $P$. digitatum (remainder unaffected). In the case of $P$. expansum, $P G$ was significantly lower, and pacC was slightly higher.

Reisolation, preservation, and identification. Cultures of the Penicillium spp. isolated from symptomatic fruit were grouped. Representative cultures were confirmed as the inoculated species via NCBI standard nucleotide BLAST of $\beta$-tubulin. cDNA of extracted RNA from tissue samples was submitted for identification and confirmed as the target sequences. Identity of sequences had 99 to $100 \%$ similarity with 99 to $100 \%$ query cover. Cultures were purified, preserved, and stored in the Penicillium spp. culture collection at the University of Pretoria.

\section{Discussion}

Nectarines became riper as fruit was stored longer (days postharvest). The increase in sugar/acid ratio should be noted. The $\mathrm{pH}$ and sugar are important regulatory factors impacting infection and
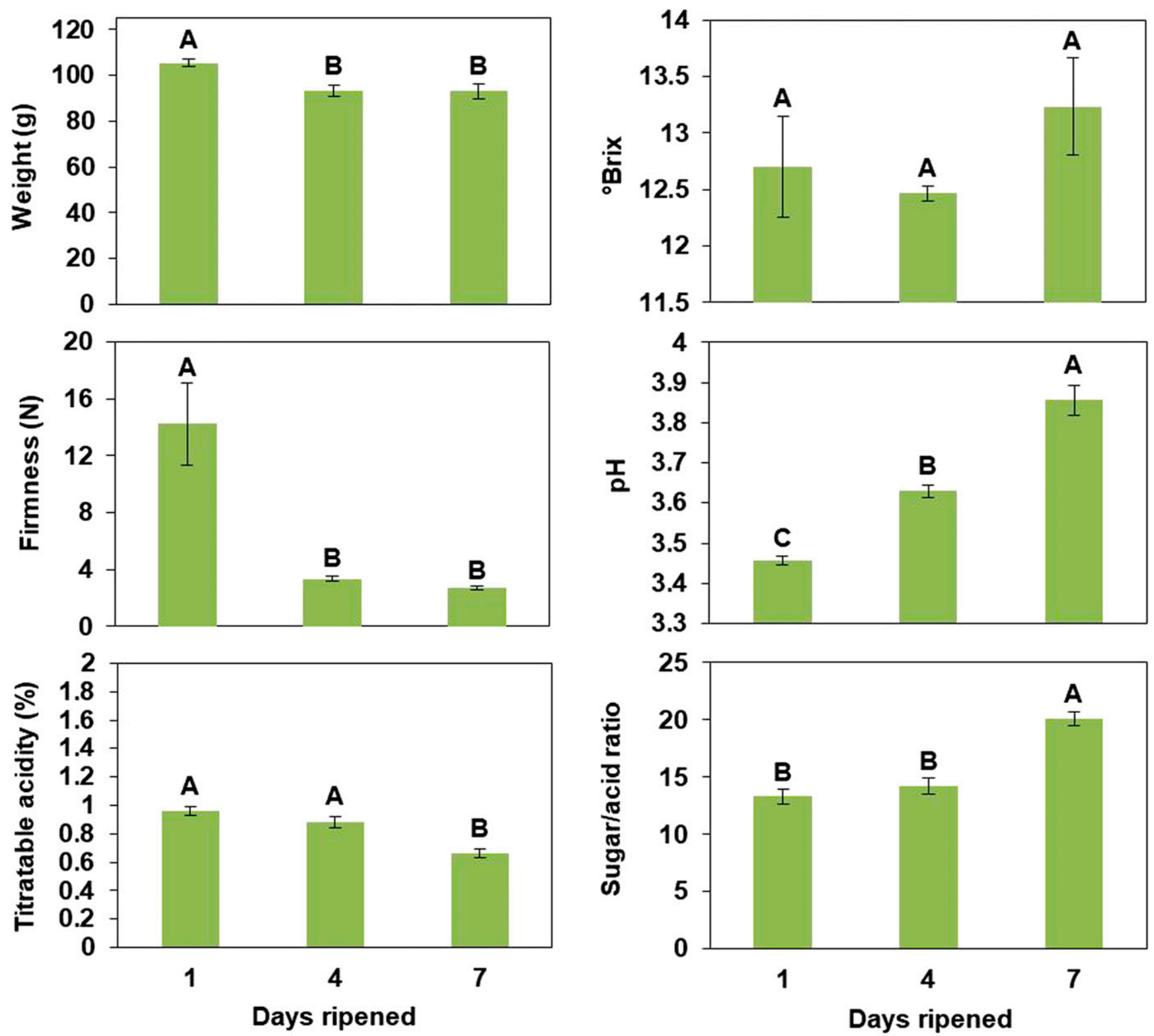

Fig. 1. Fruit indices of nectarine (cultivar Sunlite) stored at ambient conditions. Vertical bars indicate standard error. Different letters (only letters of similar case are comparable) indicate treatments that are significantly different $(P<0.05)$ based on Fisher protected least significant difference. 1,1 day postharvest; 4,4 days postharvest; 7,7 days postharvest. 
colonization of Penicillium spp. (Bi et al. 2016; Prusky et al. 2004). The large differences in fruit physiology of 1- versus 7-day postharvest fruit would provide different host environments, which should affect infection and colonization of the Penicillium spp. This was clearly the case with $P$. digitatum, but it was not necessarily so with $P$. expansum. The effect of storage on $P$. digitatum was not only observed by the increase in disease incidence and lesion diameter but also confirmed by the increase in the reference gene (increased biomass). That of $P$. expansum was unchanged by storage.

$P$. digitatum caused larger lesions at higher disease incidences on the longer stored fruit. Lesion diameter was even similar in size at 1day postharvest to that of $P$. expansum but quickly surpassed it on 4- and 7-day postharvest fruit. Previous work showed low disease incidence $(7.5 \%)$ for $P$. digitatum on Sunlite, but lesions were able to reach $\sim 55 \mathrm{~mm}$ in diameter after 7-day ambient incubation (Louw and Korsten 2016). This was particularly because fruit was 1 to 2 days postharvest. In this study, disease incidence on 1-day postharvest fruit was higher $(20 \%)$, and lesion diameter showed similarities (32.13 $\mathrm{mm}$ after 5 days of incubation). This is one of the first studies showing a significant shift in lesion diameter and disease incidence for $P$. digitatum owing to postharvest storage. Vilanova et al. (2014) reported that $P$. digitatum was able to cause lesions $\pm 45 \mathrm{~mm}$ in diameter on overmature but not immature or commercially mature Golden Smoothee apples. $P$. expansum, similar to what was observed in previous (Louw and Korsten 2016) and current work on plum (Louw and Korsten 2019), was relatively unaffected by fruit age/ripeness. Vilanova et al. (2017) reported that $P$. expansum alters the ethylene biosynthesis pathway of apple differently than $P$. digitatum and abiotic stresses (i.e., wounding). These findings indicate that these species utilize very different strategies during infection and colonization.

Scanning electron microscopy (Louw and Korsten 2016) can, to an extent, confirm the above statement. The micrographs revealed large amounts of mycelia produced by $P$. digitatum and $P$. expansum on retail-bought Crimson Glo nectarine within 48 h. P. digitatum, however, also produced large amounts of conidiophores and sporulated within the same period compared with very few conidiophores and no conidia produced by $P$. expansum. More differences were observed when both species were inoculated into Eureka seeded lemons (Louw and Korsten 2016).

Prusky et al. $(2002,2004)$ reported that $P$. expansum caused larger lesions on more acidic apple cultivars: Granny Smith $(\mathrm{pH} 3.45)$ versus Rome (pH 3.77) and Fuji (pH 4.46). This was also observed for

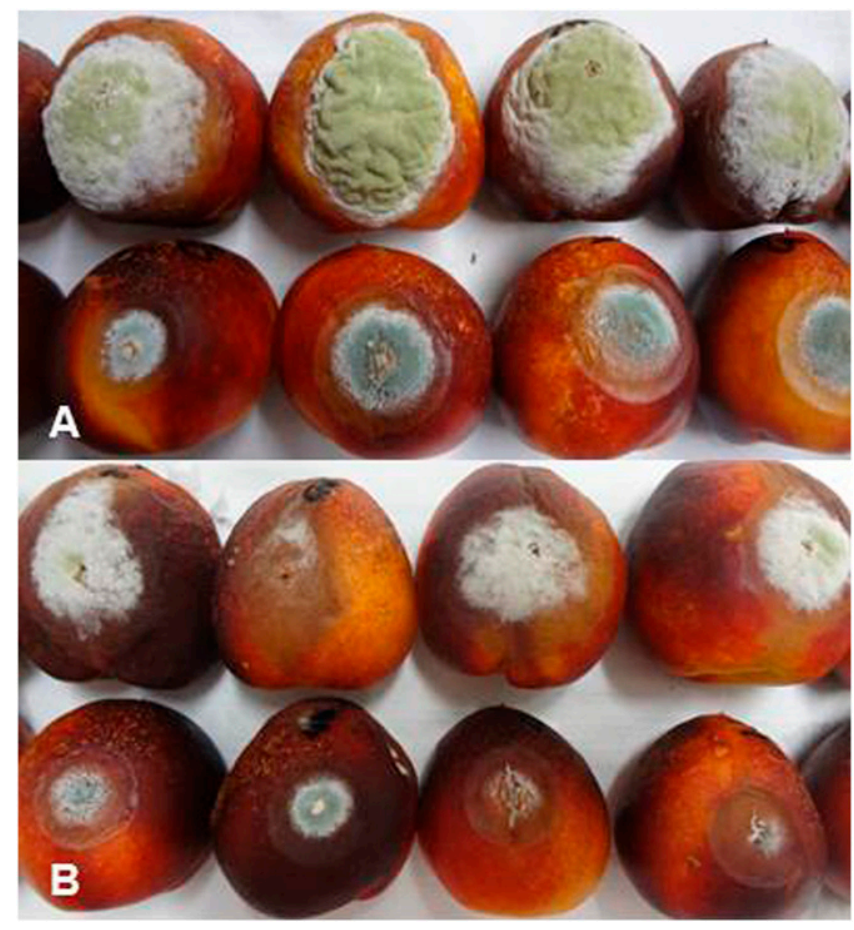

Fig. 3. Nectarine (cultivar Sunlite) inoculated with Penicillium digitatum (upper row) or Penicillium expansum (lower row) and incubated at ambient conditions. A, Four-day postharvest stored fruit incubated for 5 days. B, Seven-day postharvest stored fruit incubated for 4 days.

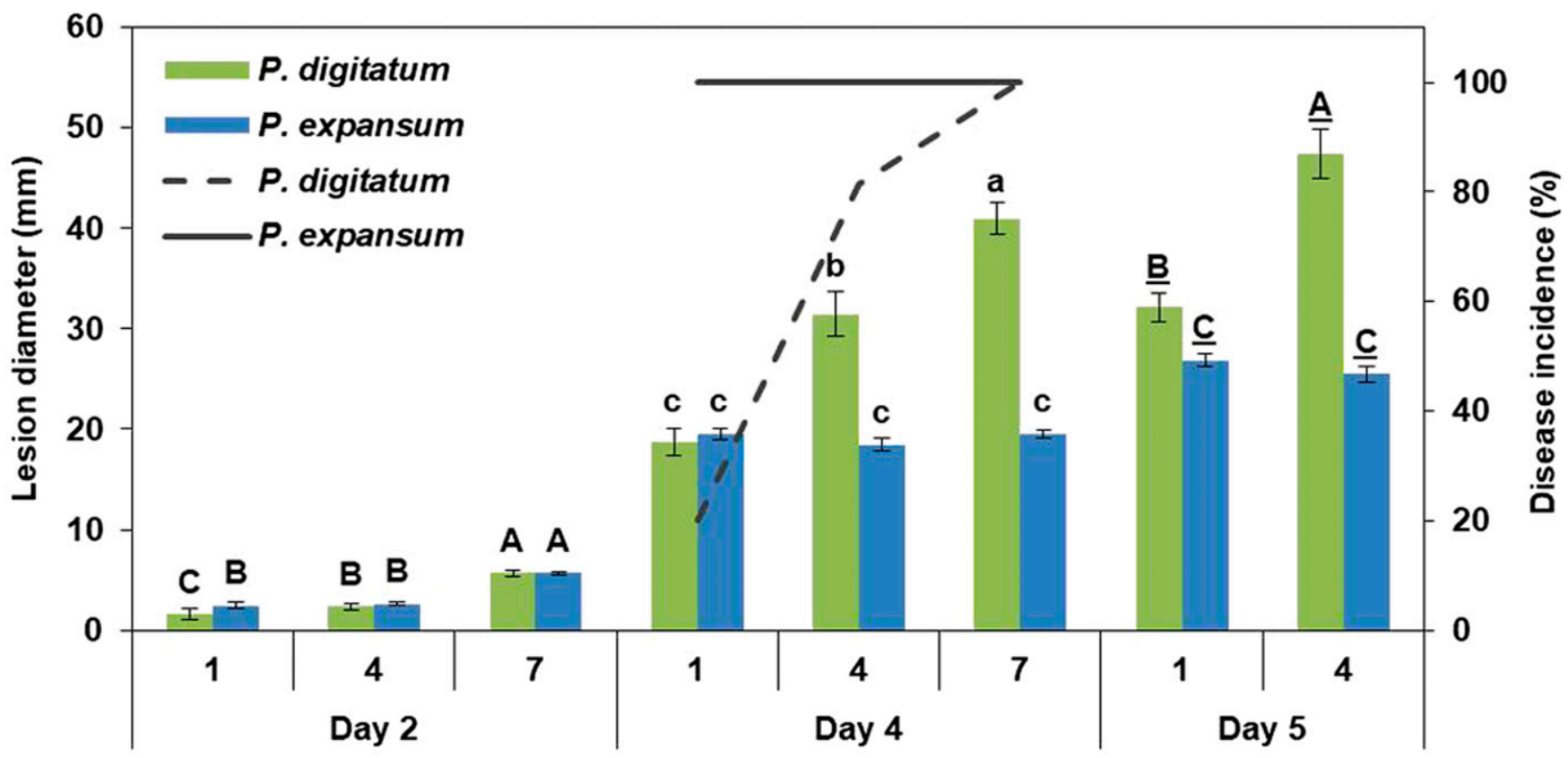

\section{1d, $4 \mathrm{~d}$ and $7 \mathrm{~d}$ stored nectarines inoculated and incubated over $5 \mathrm{~d}$}

Fig. 2. Lesion development of Penicillium spp. (Penicillium digitatum and Penicillium expansum) on nectarine (cultivar Sunlite of different postharvest storage periods incubated for 5 days under ambient conditions). Control (wound size) was subtracted from lesion diameters. Vertical bars indicate standard error. Different letters (only letters of similar case and underlining are comparable) indicate treatments that are significantly different $(P<0.05)$ based on Fisher protected least significant difference. 


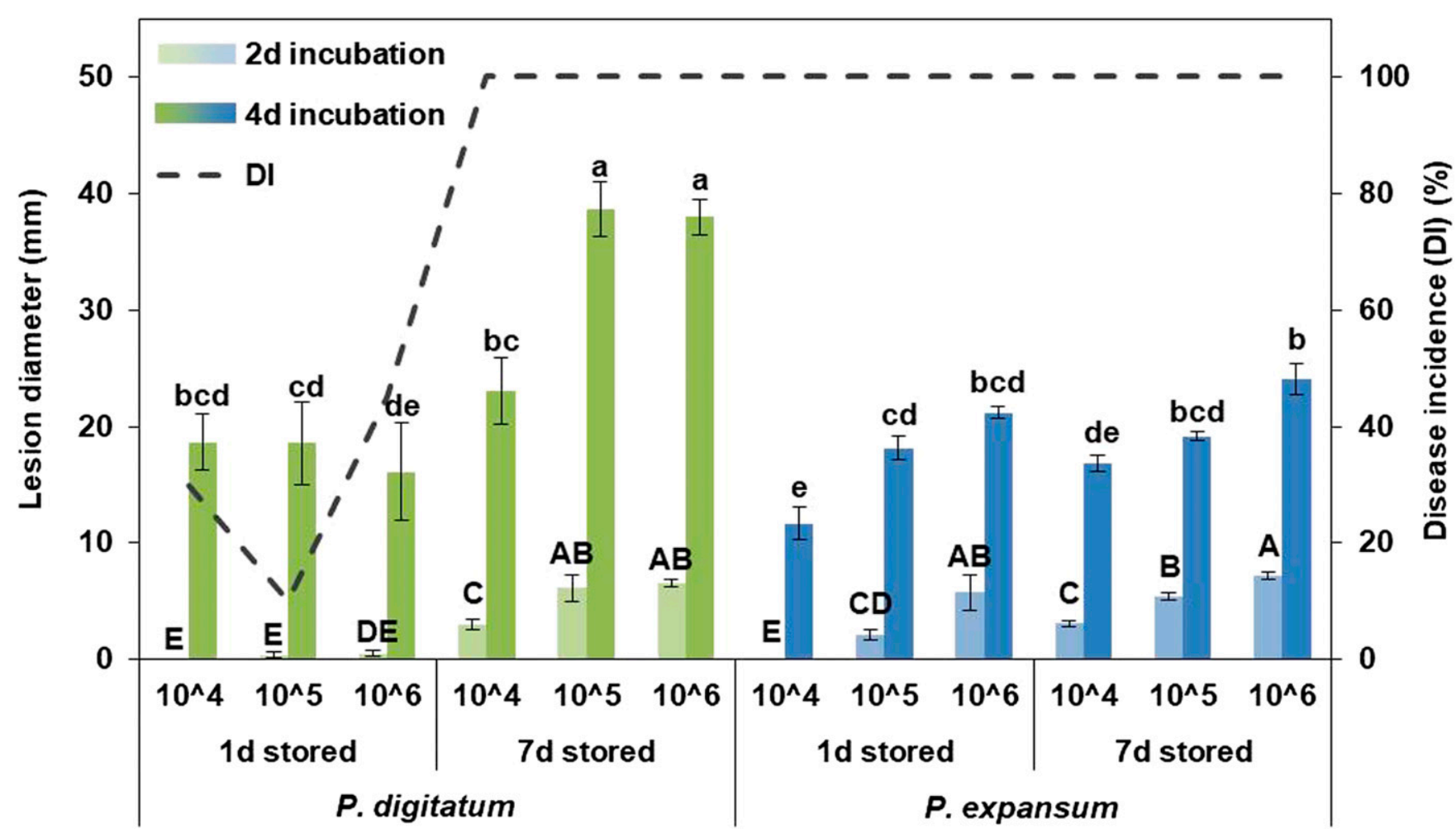

Fig. 4. Lesion diameters caused by different concentrations $\left(10^{4}\right.$ to $10^{6}$ conidia per $1 \mathrm{ml} ; 200$ to 20,000 conidia) of Penicillium spp. (Penicillium digitatum and Penicillium expansum) on nectarine (cultivar Sunlite) stored for different periods. Wounds have been subtracted from lesion diameters. Vertical bars indicate standard error. Different letters (for each pathogen evaluated, only letters of similar case are comparable) indicate treatments that are significantly different $(P<0.05)$ based on Fisher protected least significant difference. 1d, 1-day postharvest storage; 7d, 7-day postharvest storage.

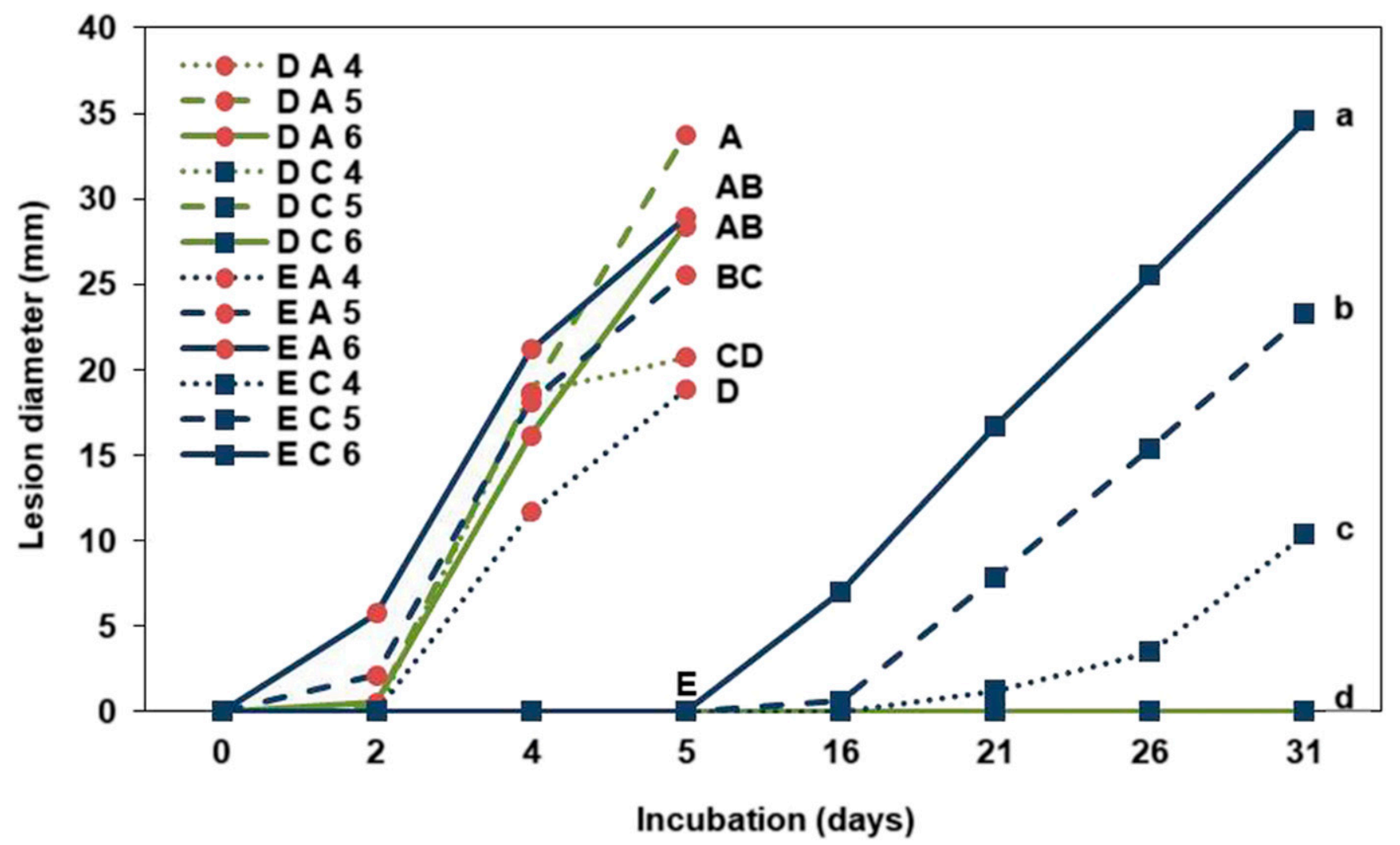

Fig. 5. Lesion diameter caused by different concentrations (4 to 6) of Penicillium digitatum (D) and Penicillium expansum (E) on nectarine (cultivar Sunlite; 1-day postharvest storage) at ambient $(\mathrm{A})$ and cold storage $(\mathrm{C})$ conditions. Wounds have been subtracted from lesion diameters. Different letters (only letters of similar case are comparable) indicate treatments that are significantly different $(P<0.05)$ based on Fisher protected least significant difference. $4,10^{4}$ conidia per $1 \mathrm{ml}(200 \mathrm{conidia}) ; 5,10^{5}$ conidia per 1 $\mathrm{ml}\left(2,000\right.$ conidia); $6,10^{6}$ conidia per $1 \mathrm{ml}(20,000$ conidia). 
$P$. digitatum when it was screened for pathogenicity on apples (Louw and Korsten 2014). Comparing current work on plum (Louw and Korsten 2019) with that of nectarine further confirmed this. Plum had $\mathrm{pH}$ values of 2.97 ( 1 day postharvest) and 3 (4 days postharvest), whereas those of nectarine were 3.46 and 3.63 ( 1 and 4 days postharvest, respectively). Lesions caused by $P$. digitatum on plum averaged 49.97 and $57.89 \mathrm{~mm}$ in diameter, respectively, compared with 32.13 and $47.40 \mathrm{~mm}$, respectively, on nectarine after 5 days of ambient incubation. Lesions caused by $P$. expansum on plum were 29.39 to $29.65 \mathrm{~mm}$ versus 25.50 to 26.26 .88 on nectarine. Although larger lesions were caused by $P$. expansum on more acidic fruits/cultivars, the change in $\mathrm{pH}$ owing to fruit storage had no effect on lesion diameter. Other factors are interacting on the response.

Modulation of $\mathrm{pH}$ was affected by fruit storage. This can primarily be ascribed to the varying $\mathrm{pH}$ values (initial) of the fruit from the different storage periods. When $\mathrm{pH}$ was at its lowest (1 day postharvest), $P$. digitatum maintained $\mathrm{pH}$, and $P$. expansum increased $\mathrm{pH}$. When $\mathrm{pH}$ was higher (4 and 7 days postharvest), $P$. digitatum decreased
$\mathrm{pH}$, whereas $P$. expansum maintained or decreased $\mathrm{pH}$. This confirms that these species will not only acidify host tissue but also, increase $\mathrm{pH}$ depending on the host environment. Colonized tissue of an acidic host can be maintained or further acidified by acidification (organic acid production and ammonium/ammonia uptake). Alternatively, the mechanism can be inverted to increase $\mathrm{pH}$ (Barad et al. 2016a; Bi et al. 2016; Prusky et al. 2004). A dual pattern of $\mathrm{pH}$ modulation has been discussed for $P$. expansum on apple (Barad et al. 2016a; Bi et al. 2016; Sánchez-Torres and GonzálezCandelas 2003).

It was noted in our study that the Penicillium spp. did not modulate $\mathrm{pH}$ to a state that would be optimal for $P G$ expression (expression of pepg 1 [endopolygalacturonase gene] of $P$. expansum was optimal at pH 4 and much lower at pH 3 to 3.5 [in vitro] [Prusky et al. 2004]) or PG activity ( $\mathrm{PG}$ isolated from $P$. expansum was active over $\mathrm{pH} \sim 3$ to 6.5 but optimal at $\mathrm{pH} 4$ to 5.5 [in vitro] [Jurick et al. 2010; Yao et al. 1996]). The $\mathrm{pH}$ at infected sites of nectarine equalized at $\sim 3.4$ to 3.5 for $P$. digitatum, and it increased to (1 day postharvest), remained at
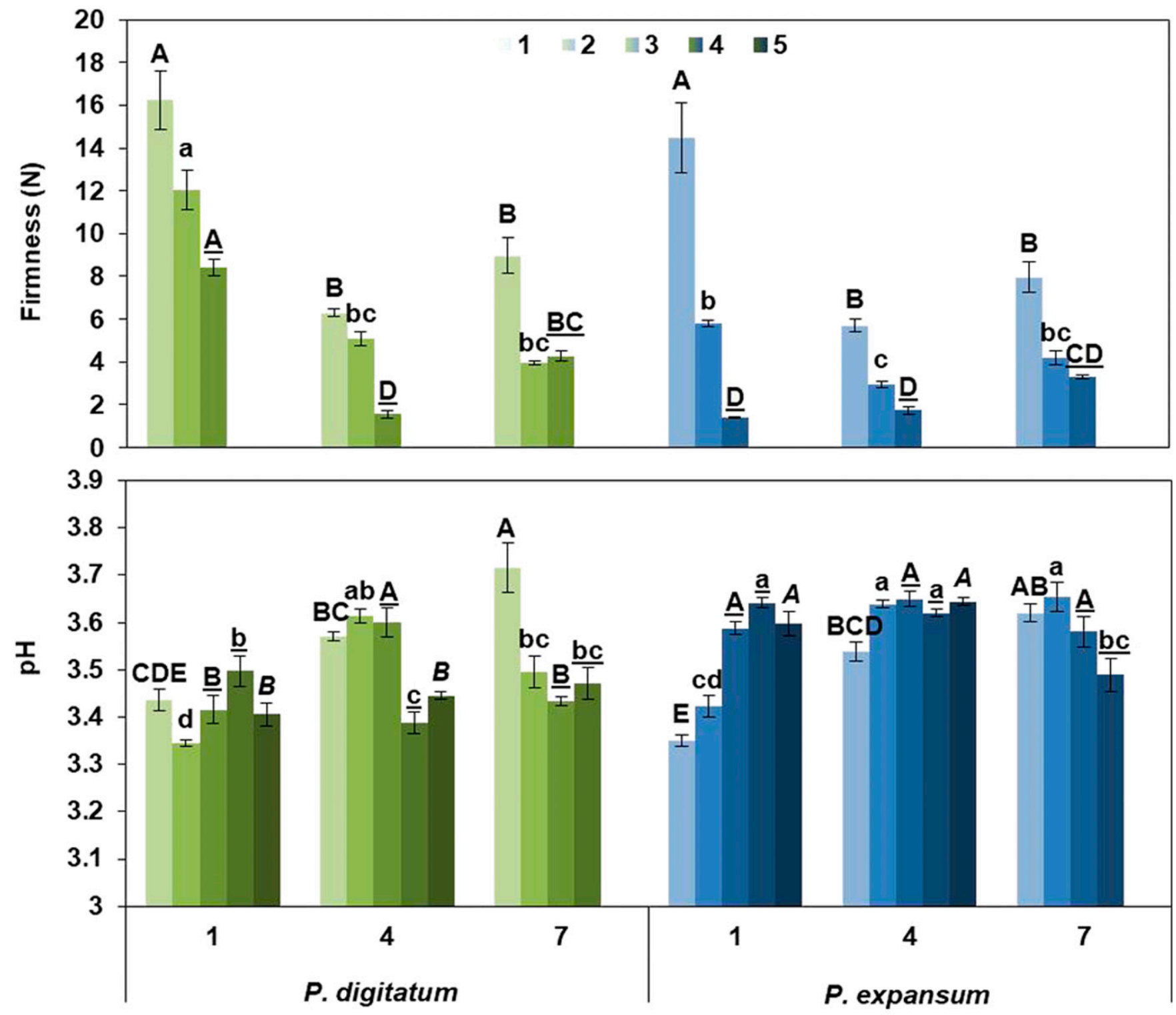

Postharvest storage (days)

Fig. 6. Firmness and pH of lesions caused by Penicillium spp. (Penicillium digitatum and Penicillium expansum) on nectarine (cultivar Sunlite) stored for different periods and incubated for 5 days (1 to 5). Vertical bars indicate standard error. Different letters (for each pathogen evaluated, only letters of similar case and underlining are comparable) indicate treatments that are significantly different $(P<0.05)$ based on Fisher protected least significant difference. 1, 1-day postharvest storage; 4, 4-day postharvest storage; 7, 7-day postharvest storage. 
(4 days postharvest), or dropped below (7 days postharvest) 3.6 for $P$. expansum. This corresponded with results of $P$. expansuminfected apple cultivars (Granny Smith $=3.64 \pm 0.01$, Gala $=$ $3.88 \pm 0.03$ [Prusky et al. 2004], and Golden Delicious = 3.6 [Sánchez-Torres and González-Candelas 2003]) and P. digitatuminfected citrus fruits $(\mathrm{Navel}=3.12 \pm 0.07$, Oro Blanco $=3.10 \pm 0.14$ [7-day incubation] [Prusky et al. 2004], and Citrus unshiu $=3.22 \pm$ 0.15 [4-day incubation] [Zhang et al. 2013]).

$P G$ expression differs depending on in vivo and in vitro studies (Barad et al. 2016b; López-Pérez et al. 2015; Sánchez-Torres and González-Candelas 2003), and PG activity will vary depending on the Penicillium spp. (Jurick et al. 2009, 2010). The $\mathrm{pH}$ of $P$. digitatumcolonized tissue of nectarine, plum (Louw and Korsten 2019), and citrus (Prusky et al. 2004; Zhang et al. 2013) was lower than that of P. expansum on nectarine, plum (Louw and Korsten 2019), and apple (Prusky et al. 2004). It is thus possible that the PG activity of $P$. digitatum is optimal at lower $\mathrm{pH}$ levels than in $P$. expansum and $P$. solitum. Future studies are needed.

The $\mathrm{pH}$ values of colonized sites were similar to the initial $\mathrm{pH}$ value of fresh nectarine ( 1 day postharvest). The $\mathrm{pH}$ value before inoculation was 3.46 compared with 3.5 ( $P$. digitatum) and 3.64 (P. expansum) after 4 days of incubation. The differences remained relatively small for 4-day postharvest fruit $\left(P\right.$. digitatum $\Delta_{\mathrm{pH}}=$ 0.24 and $P$. expansum $\Delta_{\mathrm{pH}}=0.01$ ) but increased considerably for 7-day postharvest fruit $\left(\Delta_{\mathrm{pH}}=0.39\right.$ and $\Delta_{\mathrm{pH}}=0.38$, respectively). Similarities can be drawn to apple cultivars. Barad et al. (2016a) reported $\mathrm{pH} 3.58$ at the inoculation site (P. expansum) of Golden Delicious (5 days of incubation). Prusky et al. (2004) provided $\mathrm{pH}$ values after 7 days of incubation: Fuji $=3.96$, Gala $=3.88$, Golden Delicious $=3.88$, Granny Smith $=3.64$, and Red Delicious $=$ 4.07. It was unclear how fresh and/or what the $\mathrm{pH}$ values of uninfected apples were in Barad et al. (2016a) and Prusky et al. (2004). This can be obtained from Keller et al. (2004): Fuji = 3.91, Gala $=3.86$, Golden Delicious $=3.64$, Granny Smith $=$ 3.42 , and Red Delicious $=4.10$. Although the $\mathrm{pH}$ values fluctuate depending on the incubation period, these results show that $P$. digitatum and $P$. expansum can maintain an environmental $\mathrm{pH}$ similar to that of the host. In cases where the $\mathrm{pH}$ is too high (i.e., type, cultivar, storage, or ripeness), a lowering in $\mathrm{pH}$ was evident. The $\mathrm{pH}$ of decayed tissue seems to be host (Bi et al. 2016; Prusky et al. 2004) and species specific.

$\Delta_{\mathrm{pH}}$ colonized-uncolonized for both Penicillium spp. increased from 1- to 7-day postharvest storage (from 0.06 and 0.11 to 0.53 and 0.32 ), but the $\Delta \Delta_{\mathrm{pH}}$ values were similar (between 0.01 and 0.17 ). This does not correspond with results of $P$. expansum on apple (Prusky et al. 2004) or Penicillium spp. on plum (Louw and Korsten 2019). $\Delta_{\mathrm{pH}}$ colonized-uncolonized $=0.31$ to 0.88 for apples (Prusky et al. 2004), whereas $\Delta_{\mathrm{pH}}$ colonized-control $=0.02$ to 0.24 (combining data from Keller et al. [2004] and Prusky et al. [2004]); thus, $\Delta \Delta_{\mathrm{pH}}=$ 0.29 to 0.64 . With plum, $P$. digitatum $\Delta \Delta_{\mathrm{pH}}=0.16$ to 1.8 , and $P$. expansum $\Delta \Delta_{\mathrm{pH}}=0.6$ to 1.55 . The primary reason for the large difference observed with plum was the rapid ripening of infected plum compared with slower (natural) ripening of uninfected fruit. The interference of Penicillium spp. on fruit ripening also seems to be host and species specific (Vilanova et al. 2017).

This study is one of the first to use ddPCR to quantify the expression of genes in postharvest pathology of fruit. Expression of $P$. digitatum genes showed little change at the different incubation periods (24 and $48 \mathrm{~h}$ ). There was an increase in $A C C D$ and a decrease in pac $C$. The same cannot be said about $P$. expansum, with decreases in $P G$ and pacC and an increase in $A C C D$. Results from $P$. digitatum-infected Navelina oranges (Citrus sinensis L. Osbeck) corresponded with our results. Expression of PG genes (pgl and pg2) increased and/or remained constant over a 4-day incubation period (López-Pérez et al. 2015). The downregulation of $P G$ of $P$. expansum was likewise observed on plum (Louw and Korsten 2019) and by Sánchez-Torres and González-Candelas (2003). Sánchez-Torres and González-Candelas (2003) determined the expression of two different PG genes (pepg1 and pepg2) of P. expansum from infected Golden Delicious apples (heat treated) and cultures (minimal media with apple pectin). There was no expression of pepg 1 but decreased expression of pepg2 (24 versus $48 \mathrm{~h}$ ) from their in vitro work. In vivo, there was no expression of pepgl at $24 \mathrm{~h}$ and similar (very low) expression at 48 and $72 \mathrm{~h}$, whereas expression of pepg 2 decreased over the 72 -h period. Differential expression of pepg1 and pepg 2 could have been owing to differences in environmental $\mathrm{pH}$.

Expression of $A C C D$ and pacC should decrease in an acidic environment (in vitro) but can increase when ammonium/ammonia concentrations are high, even under acidic conditions. They are, however, not similarly affected by these factors. ACCD expression is affected more by ammonium/ammonia levels and less by $\mathrm{pH}$, whereas pacC showed a stronger connection to $\mathrm{pH}$ and less to ammonium/ammonia (Barad et al. 2016a, 2016b). The low $\mathrm{pH}$ of fruit could be sufficient to describe the downregulation of pacC, but it is difficult to draw a proper correlation, because the $\mathrm{pH}$ values of infected sites showed gradual changes from 24 to $48 \mathrm{~h}\left(\Delta_{\mathrm{pH}}=0.07\right.$ to 0.1$)$.

Table 2. $\mathrm{pH}$ of uncolonized and colonized tissue of Penicillium-inoculated nectarine (cultivar Sunlite) of different storage periods

\begin{tabular}{lccc}
\hline $\begin{array}{c}\text { Incubation } \\
\text { (days), }\end{array}$ & \multicolumn{4}{c}{ Postharvest storage (days) } \\
Penicillium spp., \\
and tissue
\end{tabular}

${ }^{\mathrm{y}} \Delta_{\mathrm{pH} 1}, \mathrm{pH}$ difference between uncolonized and colonized; $\Delta_{\mathrm{pH} 2}, \mathrm{pH}$ difference between colonized and control (wounded); $\Delta \Delta_{\mathrm{pH}}$, difference between $\Delta_{\mathrm{pH} 1}$ and $\Delta_{\mathrm{pH} 2}$.

${ }^{\mathrm{z}}$ Control wounded indicates the site where fruit was inoculated with sterile Ringer's solution with $0.05 \%$ Tween 80 . Control unwounded indicates site maximum distance away from the inoculation sites. Data are displayed with standard deviation. Different letters (case dependent) are significantly different $(P<0.05)$ based on Fisher protected least significant difference. 
It is possible that an increase in ammonium levels could have contributed to the upregulation of $A C C D$. Ammonium is an important nitrogen source of Penicillium spp. (Ross and Luckner 1984). It can enhance $\mathrm{pacC}$ responsiveness, modulate environmental $\mathrm{pH}$, and induce the expression of a few genes associated with the nitrogen metabolism and cell damage (pectolytic enzymes and toxins) (Barad et al. 2016a, 2016b; Song et al. 2014). One of these is ACC, a precursor of ethylene (Glick 2014). Accumulation of ACC induces expression of ACCD (Jia et al. 2000), by which it is cleaved to produce more ammonia and $\alpha$-ketobutyrate (Glick 2014; Jia et al. 2000). Pathogen attack can result in stress ethylene, causing a host plant to accumulate ACC and undergo advanced ripening and senescence (Glick 2014).

Unlike what was observed on plum (Louw and Korsten 2019), the definite connection between infection and increased ripening could not be made, because control fruit had similar $\mathrm{pH}$ values to uncolonized tissue of infected fruit. The nectarine fruit was also harvested at an advanced mature stage (unlike with plum). The upregulation of $A C C D$ ( 24 versus $48 \mathrm{~h}$ ) was an indicator of increased ripening. Ripening could have been owing to ACC synthesized by the Penicillium spp. (Barad et al. 2016b; Yang et al. 2017) and/or the infection itself (stress ethylene) (Glick 2014). The higher expression of ACCD on fresh fruit (1 day postharvest) from 24 to $48 \mathrm{~h}$ but downregulation on 7-day postharvest fruit at $48 \mathrm{~h}$ indicates synthesis of more ACC early after harvest rather than later. It is possible that the host environment at 7 days postharvest was already at a favorable state (very ripe). Testing the nutritional composition of infected fruit (colonized and uncolonized tissue) should be considered in future work.

Fruit storage had a large effect on the expression of $P G$ and a small to no effect on the expression of $A C C D$ and pacC for both Penicillium spp. The expression of $\mathrm{creA}$ increased for $P$. digitatum but was unaffected for $P$. expansum owing to storage. Total sugar content of peach can remain constant or slightly decrease during postharvest storage (Borsani et al. 2009). Nectarine and peach cultivars contain
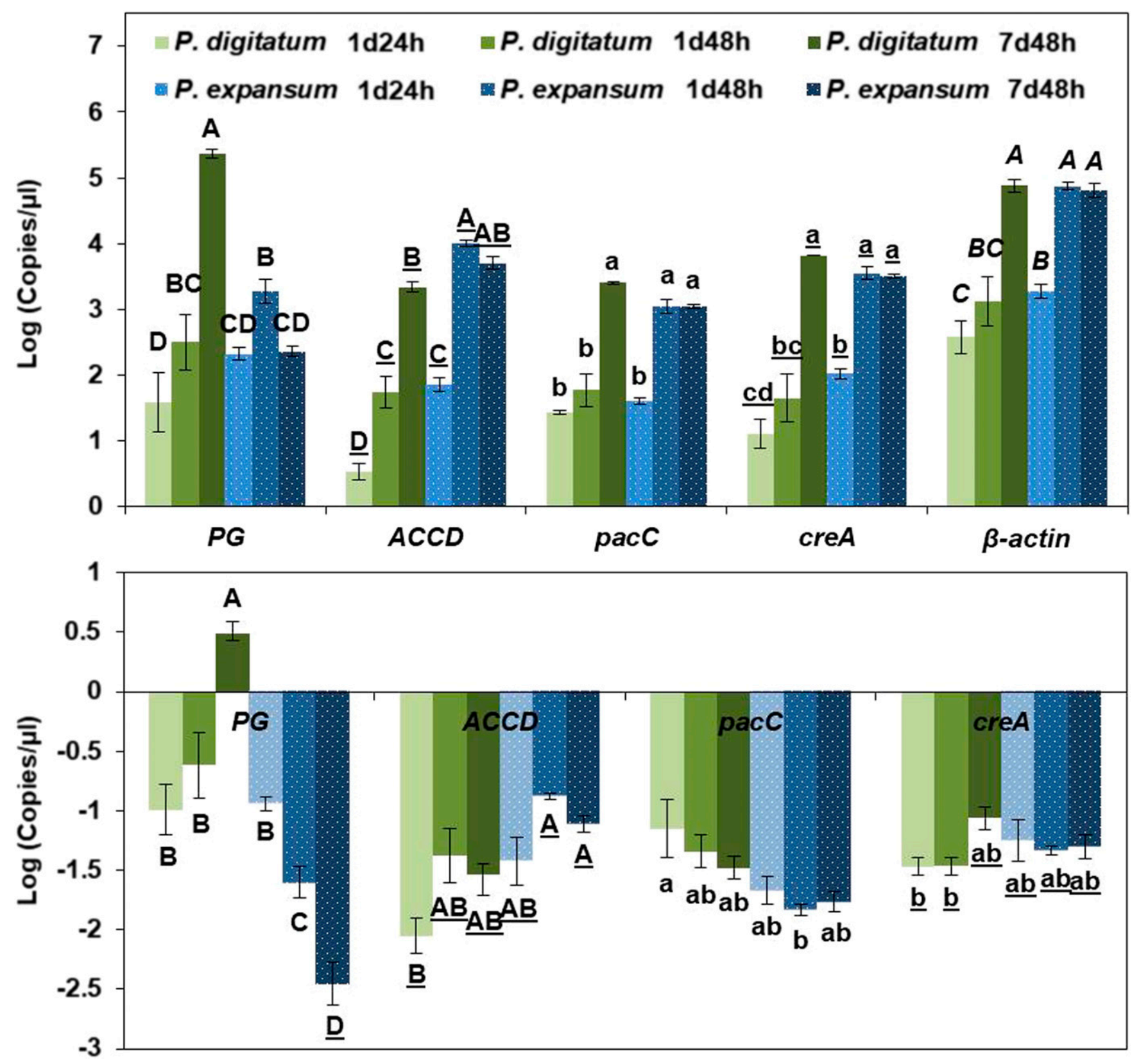

Fig. 7. Gene expression of Penicillium digitatum and Penicillium expansum when inoculated in nectarine (cultivar Sunlite) stored for different periods (1- and 7-day postharvest storage) after 24 and $48 \mathrm{~h}$ of incubation. Raw data (upper panel) were normalized (lower panel) using the reference gene ( $\beta$-actin). Vertical bars indicate standard error. Different letters (only letters of similar case, underlining, and italicizing are comparable) indicate treatments that are significantly different $(P<0.05)$ based on Fisher protected least significant difference. $P G$, polygalacturonase. 
high levels of sucrose, but fructose, glucose, and to a lesser extent, sorbitol also make up for the total sugar content (Colarič et al. 2004). Some of these sugars can significantly decrease (i.e., sucrose and sorbitol), whereas others increase (i.e., fructose and glucose) during storage (Borsani et al. 2009). The upregulation of creA indicates that there was possibly more glucose available in the 7-day postharvest fruit (Bi et al. 2016; Borsani et al. 2009). Although not significant, it corresponds with the higher ${ }^{\circ}$ Brix value of the 7-day postharvest fruit. CreA regulates the carbon catabolite repression (ensures preferentially utilization of certain carbon sources [i.e., glucose] [Fernandez et al. 2012, 2014]) but is also involved in acidification and alkalization processes (Bi et al. 2016).

Little is still known about the effect that varying carbon levels of fruit at different maturity and ripeness levels will have on $\mathrm{pH}$ modulation ( $\mathrm{Bi}$ et al. 2016). Acidification can be induced under excess sugar, even for pathogens classified with alkalinizing lifestyles. Conversely, alkalization can be induced under carbon-deprived conditions, even by acidifying pathogens (Alkan et al. 2013; Bi et al. 2016; Ment et al. 2015). Bi et al. (2016) showed that higher sucrose levels will cause $P$. expansum to produce less ammonia and more gluconic acid (in vitro). This environment will cause a decrease in expression of $A C C D$ and pacC (Barad et al. 2016a, 2016b). The decrease (not significant) in the expression of both of these genes from $P$. digitatum and the rapid drop in $\mathrm{pH}$ of lesions of 7-day postharvest fruit corresponded with this. In the case of $P$. expansum, cre $A$ and $\mathrm{pH}$ of lesions of 7-day postharvest fruit were unaffected. This corresponds with the increase in expression of pacC (P. expansum). The strong in vitro reaction observed by Bi et al. (2016) can be ascribed to the sucrose levels being very high (excess). Other factors (i.e., $\mathrm{pH}$ and ammonium) possibly played a larger part in the interaction of $P$. expansum with nectarine. The effects that environmental $\mathrm{pH}$ and nitrogen and carbon sources have on the host-pathogen interactions of different Penicillium spp. are more complex than originally expected.

The upregulation of $P G$ by $P$. digitatum and the downregulation by $P$. expansum further enforce the above statement. The higher initial $\mathrm{pH}$ of 7-day postharvest fruit (3.86) compared with 1-day postharvest fruit (3.46) would be closer to the optimal $\mathrm{pH}$ for $P G$ expression and PG activity (in vitro) (Jurick et al. 2009, 2010; Prusky et al. 2004). This can be presumed as the cause (in terms of host physiology) of the larger lesions caused by $P$. digitatum. However, this was not observed with $P$. expansum, and both species lowered the $\mathrm{pH}(P$. digitatum $=3.47 ; P$. expansum $=3.49)$ as incubation continued. $P$. digitatum lowered the $\mathrm{pH}$ of colonized sites faster and lower than $P$. expansum. Other unrevealed factors are playing a major role in this newly discovered disease interaction with its drastic increase in disease incidence and lesion diameter on stored or riper fruit.

Although similarly observed by Sánchez-Torres and GonzálezCandelas (2003), it was unexpected to see a lower expression of $P G$ from $P$. expansum over time while lesion diameter continued to increase. $P$. expansum very possibly has a stronger dependence on another mechanism to increase lesion size, such as other pectolytic enzymes or toxins. $P$. expansum is a known producer of multiple mycotoxins (i.e., citrinin, patulin, and roquefortine C) (Frisvad and Samson 2004; Pitt and Hocking 2009). The upregulation of pacC support this, because this gene plays a significant role in not only the activation of D-gluconic acid ( $\mathrm{pH}$ modulation) but also, the regulation of pathogenicity and secondary metabolites (i.e., patulin) (Barad et al. 2016a). Expression of genes involved in patulin biosynthesis of $P$. expansum also depends on specific nutritional growth conditions (Li et al. 2015). Damoglou and Campbell (1986) reported an optimal $\mathrm{pH}$ range of 3.2 to 3.8 for the production of patulin by $P$. expansum in apple juice. Tannous et al. (2016) confirmed a higher patulin production at $\mathrm{pH} 4$ compared with 2.5 and 7 on Czapek glucose agar. This is in accordance with the $\mathrm{pH}$ of colonized tissue at lesions on nectarine.

Storage or ripeness not only affected lesion diameter but also, affected disease incidence of $P$. digitatum. Many host factors (physical, biochemical, and molecular) change during postharvest storage. Although host physiology (i.e., firmness, sugar content, $\mathrm{pH}$, and nitrogen levels) provided some explanation for the increased disease incidence and lesion diameters, it is still not clear what specific factors trigger the increase on the longer stored fruit. The low and sharp decline in fruit firmness of 7-day postharvest fruit could suggest advancement in fruit senescence and thus, deterioration in host resistance and an increase in infection and colonization of $P$. digitatum. Studying host resistance (decline as fruit ripen [Prusky et al. 2016]) might reveal the true cause of the opportunistic lifestyle expressed by $P$. digitatum on nectarine.

The lifestyle of $P$. digitatum on nectarine makes it less of a concern early in a fresh produce chain but more so at the end (long storage and fruit tend to be riper). P. expansum does not follow this lifestyle on nectarine, constantly causing lesions of similar size with complete disease incidence $(100 \%)$ in nearly all cases. It was noticed that the fan in the cold room accelerated moisture loss of exposed fruit in the cold storage trials. This would have affected results. None the less, the sensitivity of $P$. digitatum to cold storage and its opportunistic lifestyle on nectarine were confirmed. This cannot, however, be said when $P$. digitatum infects and colonizes citrus (Eureka seeded lemons). Louw and Korsten (2015) revealed that, even with low concentrations $\left(6.3 \times 10^{4}\right.$ conidia per $\left.1 \mathrm{ml}\right), P$. digitatum could cause lesions of $43.8 \pm 5.6 \mathrm{~mm}$ in diameter after 26 days of cold storage $(5.0 \pm$ $0.7^{\circ} \mathrm{C}$ and $\left.86.4 \pm 4.5 \% \mathrm{RH}\right)$. The host and the environment that $P$. digitatum is exposed to thus determine its opportunistic nature.

This is one of the first reports to show and compare significant disease development (high disease incidence and large lesions) of $P$. digitatum and $P$. expansum on the same host. This is primarily owing to the discoveries showing that $P$. digitatum is pathogenic and highly aggressive on apples, pears, plums, and nectarines (Louw and Korsten 2014, 2016). It has become clear that the mechanisms used by these two pathogens to infect and colonize their hosts are quite different. The conditions (physical and host environment) that these pathogens tolerate vary, thus affecting decay development. This study also allows for the comparison of infection and colonization of $P$. digitatum on nectarine (more acidic new host) with what is already known on citrus (i.e., citrus peel [Zhang et al. 2013]).

\section{Acknowledgments}

Prof. Lise Korsten, Dr. Stacey Duvenage, and the staff of the University of Pretoria's Department of Plant and Soil Sciences are acknowledged for their support We also thank the commercial producer for participating in this study. The grant holders acknowledge that opinions, findings, and conclusions or recommendations expressed in any publication generated by National Research Foundation (NRF) supported research are those of the authors and that the NRF accepts no liability whatsoever in this regard.

\section{Literature Cited}

Alkan, N., Meng, X., Friedlander, G., Reuveni, E., Sukno, S., Sherman, A., Thon, M., Fluhr, R., and Prusky, D. 2013. Global aspects of pacC regulation of pathogenicity genes in Colletotrichum gloeosporioides as revealed by transcriptome analysis. Mol. Plant-Microbe Interact. 26:1345-1358.

Barad, S., Espeso, E. A., Sherman, A., and Prusky, D. 2016a. Ammonia activates pacC and patulin accumulation in an acidic environment during apple colonization by Penicillium expansum. Mol. Plant Pathol. 17:727-740.

Barad, S., Sela, N., Kumar, D., Kumar-Dubey, A., Glam-Matana, N., Sherman, A., and Prusky, D. 2016b. Fungal and host transcriptome analysis of pH-regulated genes during colonization of apple fruits by Penicillium expansum. BMC Genomics 17:330.

Bi, F., Barad, S., Ment, D., Luria, N., Dubey, A., Casado, V., Glam, N., Mínguez, J. D., Espeso, E. A., Fluhr, R., and Prusky, D. 2016. Carbon regulation of environmental $\mathrm{pH}$ by secreted small molecules that modulate pathogenicity in phytopathogenic fungi. Mol. Plant Pathol. 17:1178-1195.

Borsani, J., Budde, C., Porrini, L., Lauxmann, M. A., Lombardo, V. A., Murray, R., Andreo, C. S., Drincovich, M. F., and Lara, M. V. 2009. Carbon metabolism of peach fruit after harvest: Changes in enzymes involved in organic acid and sugar level modifications. J. Exp. Bot. 60:1823-1837.

Chalutz, E., and Lieberman, M. 1977. Methionine-induced ethylene production by Penicillium digitatum. Plant Physiol. 60:402-406.

Colarič, M., Štampar, F., and Hudina, M. 2004. Contents of sugars and organic acids in the cultivars of peach (Prunus persica L.) and nectarine (Prunus persica var. nucipersica Schneid.). Acta Agric. Slov. 83:53-61.

Crisosto, C. H., and Mitchell, F. G. 2011. Postharvest handling systems: Stone fruits. Pages 345-351 in: Postharvest Technology of Horticultural Crops, 3rd Ed. A. A. Kader, ed. University of California, Division of Agricultural and Natural Resources, Richmond, CA. 
DAFF. 2013. Agricultural Production Standards Act No. 119 of 1990: Standards and Requirements Regarding Control of the Export of Peach and Nectarine. Department of Agriculture, Forestry and Fisheries, Pretoria, South Africa.

Damoglou, A. P., and Campbell, D. S. 1986. The effect of $\mathrm{pH}$ on the production of patulin in apple juice. Lett. Appl. Microbiol. 2:9-11.

Fernandez, J., Marroquin-Guzman, M., and Wilson, R. A. 2014. Mechanisms of nutrient acquisition and utilization during fungal infections of leaves. Annu. Rev. Phytopathol. 52:155-174.

Fernandez, J., Wright, J. D., Hartline, D., Quispe, C. F., Madayiputhiya, N., and Wilson, R. A. 2012. Principles of carbon catabolite repression in the rice blast fungus: Tps1, Nmr1-3, and a MATE-family pump regulate glucose metabolism during infection. PLoS Genet. 8:e1002673.

Frisvad, J. C., and Samson, R. A. 2004. Polyphasic taxonomy of Penicillium subgenus Penicillium - A guide to identification of food and air-borne terverticillate Penicillia and their mycotoxins. Stud. Mycol. 49:13-102.

Glick, B. R. 2014. Bacteria with ACC deaminase can promote plant growth and help to feed the world. Microbiol. Res. 169:30-39.

Jia, Y.-J., Ito, H., Matsui, H., and Honma, M. 2000. 1-aminocyclopropane-1carboxylate (ACC) deaminase induced by ACC synthesized and accumulated in Penicillium citrinum. Biosci. Biotechnol. Biochem. 64:299-305.

Jia, Y.-J., Kakuta, Y., Sugawara, M., Igarashi, T., Oki, N., Kisaki, M., Shoji, T., Kanetuna, Y., Horita, T., Matsui, H., and Honma, M. 1999. Synthesis and degradation of 1-aminocyclopropane-1-carboxylic acid by Penicillium citrinum. Biosci. Biotechnol. Biochem. 63:542-549.

Jurick, W. M., Vico, I., Gaskins, V. L., Garrett, W. M., Whitaker, B. D., Janisiewicz, W. J., and Conway, W. S. 2010. Purification and biochemical characterization of polygalacturonase produced by Penicillium expansum during postharvest decay of 'Anjou' pear. Biochem. Cell Biol. 100:42-48.

Jurick, W. M., Vico, I., McEvoy, J. L., Whitaker, B. D., Janisiewicz, W., and Conway, W. S. 2009. Isolation, purification, and characterization of a polygalacturonase produced in Penicillium solitum-decayed 'Golden Delicious' apple fruit. Phytopathology 99:636-641.

Kader, A. A. 2011. Postharvest biology and technology: An overview. Pages 39-48 in: Postharvest Technology of Horticultural Crops, 3rd Ed. A. A. Kader, ed. University of California, Division of Agricultural and Natural Resources, Richmond, CA.

Keller, S. E., Chirtel, S. J., Merker, R. I., Taylor, K. T., Tan, H. L., and Miller, A. J. 2004. Influence of fruit variety, harvest technique, quality sorting, and storage on the native microflora of unpasteurized apple cider. J. Food Prot. 67: 2240-2247.

Li, B., Zong, Y., Du, Z., Chen, Y., Zhang, Z., Qin, G., Zhao, W., and Tian, S. 2015. Genomic characterization reveals insights into patulin biosynthesis and pathogenicity in Penicillium species. Mol. Plant-Microbe Interact. 28:635-647.

López-Pérez, M., Ballester, A.-R., and González-Candelas, L. 2015. Identification and functional analysis of Penicillium digitatum genes putatively involved in virulence towards citrus fruit. Mol. Plant Pathol. 16:262-275.

Louw, J. P., and Korsten, L. 2014. Pathogenic Penicillium spp. on apples and pears. Plant Dis. 98:590-598.

Louw, J. P., and Korsten, L. 2015. Pathogenicity and host susceptibility of Penicillium spp. on citrus. Plant Dis. 99:21-30.

Louw, J. P., and Korsten, L. 2016. Postharvest decay of nectarine and plum caused by Penicillium spp. Eur. J. Plant Pathol. 146:779-791.

Louw, J. P., and Korsten, L. 2019. Impact of ripeness on the infection and colonisation of Penicillium digitatum and $P$. expansum on plum. Postharvest Biol. Technol. 149:148-158.

Ma, Z., Luo, Y., and Michailides, T. J. 2003. Nested PCR assays for detection of Monilinia fructicola in stone fruit orchards and Botryosphaeria dothidea from pistachios in California. J. Phytopathol. 151:312-322.

Marcos, J. F., González-Candelas, L., and Zacarías, L. 2005. Involvement of ethylene biosynthesis andperception in the susceptibility of citrus fruits to Penicillium digitatum infection and theaccumulation of defence-related mRNAs. J. Exp. Bot. 56:2183-2193.

Ment, D., Alkan, N., Luria, N., Bi, F. C., Reuveni, E., Fluhr, R., and Prusky, D. 2015. A role of AREB in the regulation of PACC-dependent acid-expressedgenes and pathogenicity of Colletotrichum gloeosporioides. Mol. PlantMicrobe Interact. 28:154-166.

Navarro, D., Díaz-Mula, H. M., Guillén, F., Zapata, P. J., Castillo, S., Serrano, M., Valero, D., and Martínez-Romero, D. 2011. Reduction of nectarine decay caused by Rhizopus stolonifer, Botrytis cinerea and Penicillium digitatum with Aloe vera gel alone or with the addition of thymol. Int. J. Food Microbiol. 151:241-246.

Pitt, J. I., and Hocking, A. D. 2009. Fungi and Food Spoilage, 3rd Ed. Springer Science + Business Media, London, England.

Prusky, D. 1996. Pathogen quiescence in postharvest diseases. Annu. Rev. Phytopathol. 34:413-434.

Prusky, D., McEvoy, J. L., and Conway, W. S. 2002. Local pH modulation by pathogens as a mechanism to increase virulence. Sixth European Conference of Fungal Genetics. Pisa, Italy, Abstract 319 .

Prusky, D., McEvoy, J. L., Saftner, R., Conway, W. S., and Jones, R. 2004 Relationship between host acidification and virulence of Penicillium spp. on apple and citrus fruit. Phytopathology 94:44-51.

Prusky, D. B., Bi, F., Moral, J., and Barad, S. 2016. How does host carbon concentration modulate the lifestyle of postharvest pathogens during colonization? Front. Plant Sci. 7:1306.

Restuccia, C., Giusino, F., Licciardello, F., Randazzo, C., Caggia, C., and Muratore, G. 2006. Biological control of peach fungal pathogens by commercial products and indigenous yeasts. J. Food Prot. 69:2465-2470.

Ross, W., and Luckner, M. 1984. Relationship between proton extrusion and fluxes of ammonium ions and organic acids in Penicillium cyclopium. J. Gen. Microbiol. 130:1007-1014.

Sánchez-Torres, P., and González-Candelas, L. 2003. Isolation and characterization of genes differentially expressed during the interaction between apple fruit and Penicillium expansum. Mol. Plant Pathol. 4:447-457.

Scholtz, I., and Korsten, L. 2016. Profile of Penicillium species in the pear supply chain. Plant Pathol. 65:1126-1132.

Snowdon, A. L. 2010. A Colour Atlas of Post-Harvest Diseases and Disorders of Fruit and Vegetables, Vol. 1, General Introduction \& Fruits. Manson Publishing Ltd., London, England.

Song, X., She, X., Yue, M., Liu, Y., Wang, Y., Zhu, X., and Huang, A. 2014. Involvement of copper amine oxidase $(\mathrm{CuAO})$-dependent hydrogen peroxide synthesis in ethylene-induced stomatal closure in Vicia faba. Russ. J. Plant Physiol. 61:390-396.

Stange, R. R., Midland, S. L., Sims, J. J., and McCollum, T. G. 2002. Differential effects of citrus peel extracts on growth of Penicillium digitatum, P. italicum, and $P$. expansum. Physiol. Mol. Plant Pathol. 61:303-311.

Tannous, J., Atoui, A., El Khoury, A., Francis, Z., Oswald, I. P., Puel, O., and Lteif, R. 2016. A study on the physicochemical parameters for Penicillium expansum growth and patulin production: Effect of temperature, $\mathrm{pH}$, and water activity. Food Sci. Nutr. 4:611-622.

Untergasser, A., Nijveen, H., Rao, X., Bisseling, T., Geurts, R., and Leunissen, J. A. 2007. Primer3Plus, an enhanced web interface to Primer3. Nucleic Acids Res. 35:W71-W74.

USDA. 2017. Fresh peaches and cherries: World markets and trade. https://apps fas.usda.gov/psdonline/circulars/StoneFruit.pdf

Vilanova, L., Vall-Llaura, N., Torres, R., Usall, J., Teixidó, N. Larrigaudière, C., and Giné-Bordonaba, J. 2017. Penicillium expansum (compatible) and Penicillium digitatum (non-host) pathogen infection differentially alter ethylene biosynthesis in apple fruit. Plant Physiol. Biochem. 120:132-143.

Vilanova, L., Viñas, I., Torres, R., Usall, J., Buron-Moles, G., and Teixidó, N. 2014. Increasing maturity reduces wound response and lignification processes against Penicillium expansum (pathogen) and Penicillium digitatum (non-host pathogen) infection in apples. Postharvest Biol. Technol. 88:54-60.

Yang, J., Giné-Bordonaba, J., Vilanova, L., Teixidó, N., Usall, J., Larrigaudière, C., and Torres, R. 2017. An insight on the ethylene biosynthetic pathway of two major fruit postharvest pathogens with different host specificity: Penicillium digitatum and Penicillium expansum. Eur. J. Plant Pathol. 149: 575-585.

Yao, C., Conway, W. S., and Sams, C. E. 1996. Purification and characterization of a polygalacturonase produced by Penicillium expansum in apple fruit Phytopathology 86:1160-1166.

Zhang, T., Sun, X., Xu, Q., Candelas, L. G., and Li, H. 2013. The pH signalling transcription factor $\mathrm{pacC}$ is required for full virulence in Penicillium digitatum. Appl. Microbiol. Biotechnol. 97:9087-9098.

Zmienko, A., Samelak-Czajka, A., Goralski, M., Sobieszczuk-Nowicka, E., Kozlowski, P., and Figlerowicz, M. 2015. Selection of reference genes for qPCR- and ddPCR-based analyses of gene expression in senescing barley leaves. PLoS One 10:e0118226. 